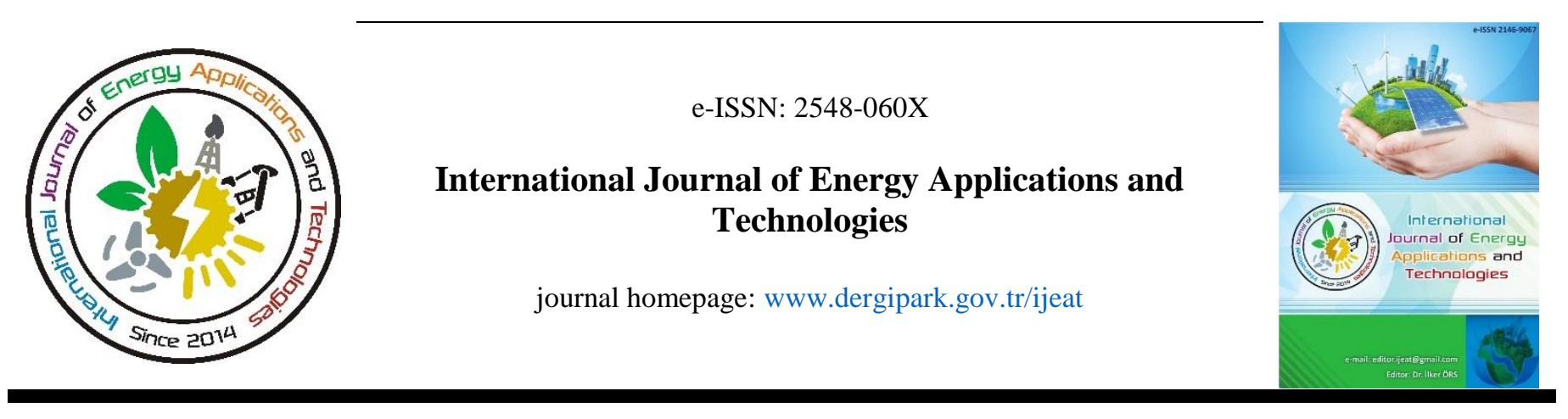

Original Research Article

\title{
Hydrogen production from groundnut shell via circulating fluidized bed technology
}

\author{
B. Can Lütfüoğlu ${ }^{1,2}$, Esat Pehlivan ${ }^{3}$, Zuhal Akyürek ${ }^{4}$, Ali Ö. Akyüz ${ }^{5 *}$, Afşin Güngör ${ }^{6}$ \\ ${ }^{I}$ Department of Physics, Akdeniz University, 07058 Antalya, Turkey \\ ${ }^{2}$ Department of Physics, University of Hradec Králové, 50003 Hradec Kralove, Czechia \\ ${ }^{3}$ Faculty of Physics and Astronomy, Freia Laboratory, Uppsala University, 75120, Uppsala \\ ${ }^{4}$ Faculty of Engineering and Architecture, Burdur Mehmet Akif Ersoy University, Burdur, Turkey \\ ${ }^{5}$ Bucak Emin Gulmez TSV Higher School, Burdur Mehmet Akif Ersoy University, Burdur, Turkey \\ ${ }^{6}$ Department of Mechanical Engineering, Akdeniz University, 07058 Antalya, Turkey
}

\author{
ARTICLE INFO \\ * Corresponding author \\ aakyuz@mehmetakif.edu.tr \\ Received October 4, 2020 \\ Accepted December 31, 2020 \\ Published by Editorial Board \\ Members of IJEAT \\ (C) This article is distributed by \\ Turk Journal Park System under \\ the CC 4.0 terms and conditions. \\ doi: 10.31593/ijeat.804913
}

\begin{abstract}
In this study, hydrogen production performances of groundnut shells in a circulating fluidized bed gasifier is evaluated by employing a previously developed and validated model. Basically, we simulate a circulating fluidized bed gasification system that is connected to a water-gas shift reactor, for hydrogen purification with the gasifier temperature of $1150 \mathrm{~K}$. We find that the amount of hydrogen gas produced from circulating fluidized bed gasification of groundnut shells increases from $49.25 \mathrm{kmol}$ to $68.83 \mathrm{kmol}$ (per $1000 \mathrm{~kg}$ of raw groundnut shells) when the gasifier is integrated with water-gas shift reactor. We observe that it is possible to obtain a high yield of hydrogen gas from the gasification of groundnut shells. Therefore, we conclude that the groundnut shell is a remarkable feedstock for bioenergy.
\end{abstract}

Keywords: Circulating fluidized bed gasification; Groundnut shell; Sustainable energy technology; Hydrogen purification

\section{Introduction}

The depletion of fossil fuel resources and climate changes as a consequence of increasing environmental pollution have increased the attention on environmentally friendly energy resources and sustainable conversion technologies. The International Energy Agency's World Energy Outlook in 2016 reported that the share of biomass accounts for $9.7 \%$ of the global energy mix in the world. This ratio is far behind the three main energy sources, namely, $31.7 \%$ oil, $28.1 \%$ coal and $21.6 \%$ natural gas in the global energy supply [1]. Renewable energy sources are evaluated in terms of zeroemission, infiniteness, and easy applicability aspects. Biomass is of great potential worldwide with respect to sustainable energy supply, given its high availability, renewable status and the possibility of productively utilizing waste materials [2-4]. The term "biomass" refers to carbonaceous materials derived from agricultural crops, forestry, agro-industrial, and domestic wastes. Fuels derived from biomass resources reduce net $\mathrm{CO}_{2}$ emissions during their processing owing to their inherent carbon-neutral nature. Hence, plentiful biomass resources are good candidates for the siting of facilities to produce green energy. Nowadays, intensive research has been conducting on the energy production of biomass as an alternative to fossil fuels. A variety of methods such as biomass gasification, biomass pyrolysis, biomass liquefaction etc. are used in hydrogen production [5-7]. Note that hydrogen is a significant 
renewable product gas and biomass is a rich source of hydrogen [8].

Gasification is one of the major biomass utilization technologies to produce high-quality gas. It converts biomass waste into a clean and usable form of energy. It is partly a process of thermal oxidation resulting in the production of gaseous products with high flammability properties [9]. The process of gasification results in a synthesis gas comprising various combustible gases such as hydrogen, oxygen, and methane [10]. Because hydrogen is emerging as a clean and sustainable fuel that can be used to control carbon emission, it has gained increasing interest in the industry [11-15]. Hydrogen has approximately three times higher heating value than that of natural gas [16]. However, hydrogen is not readily available in nature. About all the hydrogen production is derived from fossil fuel hydrocarbon reforming, particularly natural gas. Therefore, biomass is accepted an advantageous and sustainable option to produce hydrogen gas through gasification technologies [17, 18].

Fluidized bed technology is widely used in gasification because of its various advantages including high heat transfer, uniform and controllable temperature, favorable gas-solid contact and fuel flexibility [19-20]. Fluidized bed gasification (FBG) of biomass by using air-steam mixture as the gasifying agent is an economically available potential solution to produce syngas with high hydrogen content. The partial combustion of biomass in the gasifier can be converted to an automatic thermal process by providing the necessary energy for the process [21]. Several experimental studies have reported that feeding a stream of steam with airflow during FBG of biomass results in improvements in the gas quality [22-25].

Groundnut shell is one of the waste biomass materials having great potential for commercial use [26]. Worldwide production of groundnut was about 42.8 million tons in 2016. China is the leading producer of groundnut in the world. In 2016, it is recorded their production reached 16.7 million tons. This value corresponded $39 \%$ of the world's total production. India, Nigeria, and USA are other important producer countries with 6.9 million tons (16\%), 3.0 million tons $(7 \%)$ and 2.6 million tons $(6 \%)$ of groundnut production, respectively [27].

Mathematical modeling can be performed for different purposes, from the initial design of an industrial process to the final design of a specific process [28-31]. Simulation of gasification processes help to observe a comprehensive understanding of the chemical and physical mechanisms of the gasification systems, therefore leads to the design of new systems in the best possible way which saves money and time. Numerous studies have been performed on simulation and modeling of FBG systems [32-34]. Gasification performance was investigated in different particle size of biomass wastes, thermal conditions and with various catalysts [35, 36]. However, limited work has been conducted on the thermal transformation of groundnut shells. The studies have mostly focused on combustion performance of groundnut shells while a few studies have been carried out evaluating groundnut shell as an energy source through gasification and hydrogen production [26, 37, 38].

As a consequence of environmental pollution, global warming and the depletion of fossil sources, mankind should use renewable and nature friendly energy sources. Without wasting time, the use of biomass resources has to become an appropriate alternative for renewable energy production. Its renewable nature makes biomass a promising potential source for sustainable hydrogen production. With this motivation, in this study, we employ a previously developed circulating FBG model [36], and we investigate the gasification performance and hydrogen production potential of the groundnut shells. We utilize air and steam in the gasification model. Then, we include a water-gas shift (WGS) reactor as the gasification agent for the hydrogen purification to the model. We perform the simulation in the gasification process with the optimal rates that are accepted to be $100 \%$ for carbon conversion efficiency.

\section{Simulation and Validation}

In this article, we employ a previously developed [36] and validated [39] two-dimensional numerical model to evaluate the performance of groundnut shell gasification and we examine the hydrodynamic efficiency of circulating fluidized bed (CFB) biomass gasifier. We demonstrate the flowchart of the model in Fig. 1. We assume that all of the reactions in biomass gasifiers are thermodynamically balanced with each other. In order to avoid unnecessary repetition, we do not give these reactions in this article, but one can find them in Table 1 [33]. Furthermore, we assume that the process of gasification is a single reaction in this model. We use the elemental balances and the equilibrium ratio between the reactions to evaluate the composition of the produced gas. Note that, we assume that the gasifier works isothermally and therefore, the chemical equilibrium is provided. In the model, we employ a combined relaxation Newton-Raphson method with the help of Visual Basic Net.

Table 1. The results of the FBG model for $1000 \mathrm{~kg}$ of

\begin{tabular}{ccccc} 
& \multicolumn{3}{c}{ groundnut shell usage } \\
\cline { 2 - 5 } Syngas & \multicolumn{2}{c}{ Gasification } & \multicolumn{3}{c}{ WGS } \\
\cline { 2 - 5 } & (wt. \%) & kmol & $\begin{array}{c}\text { Amount } \\
\text { (wt. \%) }\end{array}$ & kmol \\
\hline $\mathrm{H}_{2}$ & 49.25 & 49.25 & 60.18 & 68.83 \\
$\mathrm{CO}$ & 44.40 & 42.40 & 20.11 & 23.00 \\
$\mathrm{CH}_{4}$ & 0 & 0 & 0 & 0 \\
$\mathrm{CO}_{2}$ & 0.039 & 0.04 & 17.00 & 19.44 \\
$\mathrm{H}_{2} \mathrm{O}$ & 0.122 & 0.12 & 0 & 0 \\
$\mathrm{~N}_{2}$ & 3.340 & 3.34 & 2.72 & 3.10 \\
\hline
\end{tabular}




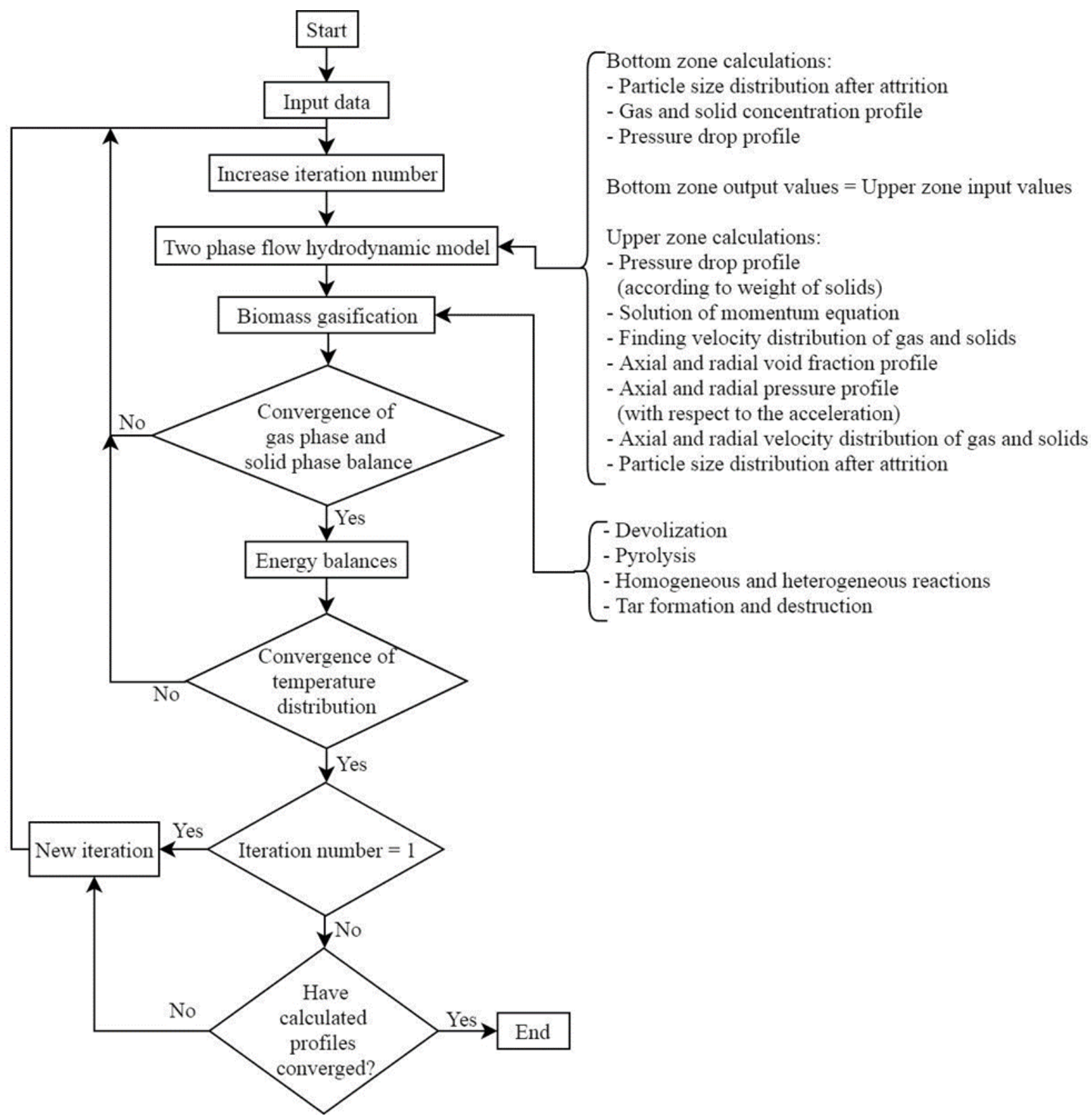

Fig. 1. Flowchart of the numerical model [36]

According to the flowchart, the model requires that syngas composition should be known at the beginning of the calculation. After entering the operation parameters such as steam-to-fuel ratios, air-to-fuel ratios and reactor temperatures, the model performs calculations for $\mathrm{H}_{2} / \mathrm{CO}$ ratio. If the calculations converge to a solution, the program saves the results to a file and stops. As a final step, the model validates the desired $\mathrm{H}_{2} / \mathrm{CO}$ ratio. If this ratio satisfies the criteria, the program computes the higher heating value (HHV) of the resulting syngas composition as well as hot and cold gas efficiencies of the system.

$\mathrm{H}_{2}, \mathrm{CO}, \mathrm{H}_{2} \mathrm{~S}, \mathrm{CH}_{4}$ and the sum of the heating values of the individual combustible constituents are used to calculate
HHV of the synthesis gas. Numerous references can easily be found concerning in various temperatures of the enthalpies and the heating values of these gases [40]. In our study, $\mathrm{H}_{2} \mathrm{~S}$ and $\mathrm{CH}_{4}$ possess very small amount, therefore, we neglect them and calculate the heating value without their effects. We take the range of the gasifier temperature in between 977$1153 \mathrm{~K}$. Note that, the efficiency of gasification depends on temperature, for example at low temperature, the system is less effective and the tar content of the gas is excessive. The model results were also compared with the experimental results of Subbaiah et al. who have carried out CFB gasification experiments for groundnut shells under similar operational conditions. 


\section{Results and Discussion}

Climate change concerns have triggered the interest in clean energy technologies that meet the environmental and political requirements. Gasification technology provides conversion of biomass into gaseous secondary energy carriers via partial oxidation at high temperature. There are many power plants reported in literature having circulating FBGs connected to large conventional boilers. In this work, we have studied the production of hydrogen gas from groundnut shells in a circulating FBG using a previously developed and validated numerical model. The model results for syngas composition were also compared with the experimental results of CFB gasification of groundnut shells under similar operational conditions.

The water gas shift is a significant reaction widely employed in industry for upgrading the syngas, where hydrogen production rate is increased, and carbon monoxide concentration is reduced by conversion of carbon monoxide to carbon dioxide. We have employed a WGS reactor for the purification of $\mathrm{H}_{2}$. We assumed that the produced syngas from the gasification process penetrates the WGS reactor with the steam feed in order to purify $\mathrm{H}_{2}$. In Fig. 2, we illustrate the schematic representation of the gasification process.

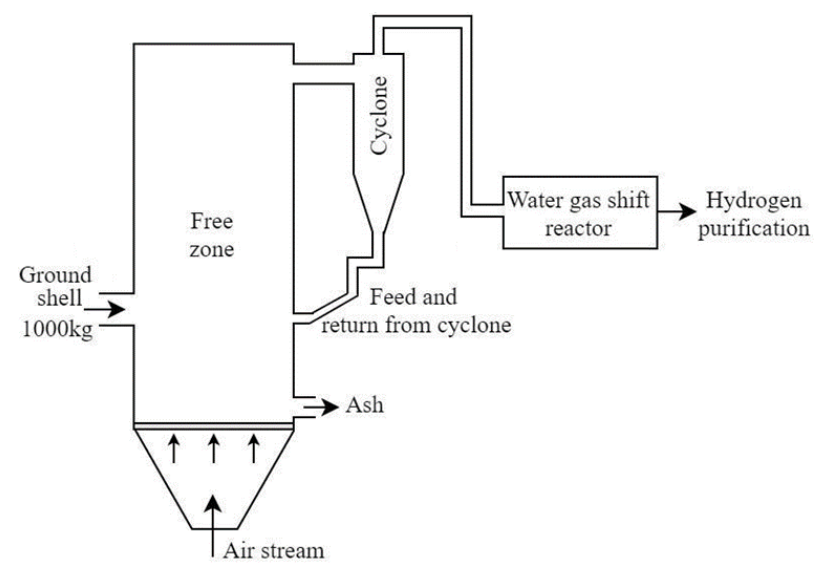

Fig. 2. Schematic representation of gasification process

In correspondence with general biomass characteristics, groundnut shells have high $\mathrm{C}$ and $\mathrm{O}$ contents and low $\mathrm{H} 2$ content. In [41], Kirubakaran et al. announce that a groundnut shell is composed of $48.3 \%$ Carbon, $39.4 \%$ Oxygen, 5.7\% Hydrogen, $0.8 \%$ Nitrogen.

We executed the FBG model and tabulated the results for $1000 \mathrm{~kg}$ of groundnut in Table 1 . We observe that $\mathrm{H}_{2}$ has the highest amount $(49.25 \%)$ in the syngas composition followed by CO $(44.40 \%)$. Comparison of the model results with previous experimental data (Subbaiah et al.) were in good agreement with the experimental results for groundnut shells $\left(\mathrm{H}_{2} ; 52.02 \%\right.$; $\left.\mathrm{CO} ; 48.99 \%\right)$ [42]. High $\mathrm{CO}$ amount is an undesirable condition due to its adverse effect on both carbon footp rint and hydrogen production. After the gasification reactor, syngas enters the WGS as a second reactor in order to reduce the $\mathrm{CO}$ ratio and increase $\mathrm{H}_{2}$ production. The results of the FBG model integrated with the WGS reactor reveal an increase in $\mathrm{H}_{2}$ amount from $49.25 \%$ to $60.18 \%$. The amount of $\mathrm{CO}$ decreases from $44.40 \%$ to $20.11 \%$, while the amount of $\mathrm{CO}_{2}$ increases to $17.00 \%$ due to the integration of the WGS reaction. As a result, the developed mathematical modeling result is obtained by purifying $68.83 \mathrm{kmol} \mathrm{H}_{2}$ gas from $1000 \mathrm{~kg}$ of groundnut shell. The gasification efficiency and $\mathrm{HHV}$ are calculated as $80.29 \%$ and $26.18 \mathrm{MJ} / \mathrm{kg}$, respectively.

\section{Conclusion}

Hydrogen gas is thought to be one of the clean, and hence, a favorable energy source in the future. Recently, an increasing number of investigations on various hydrogen purification methods are being investigated. One of them is the biomass gasification, which is a very effective method. In this article, a numerical model of circulating FBG system is employed to evaluate the hydrogen purification production performance from the groundnut shells. This investigation shows that the $\mathrm{O}_{2}$ content of groundnut shell residues is a significant factor in syngas production, mainly in hydrogen gas production. $1000 \mathrm{~kg}$ of gasified groundnut shells resulted in $68.83 \mathrm{kmol}$ $\mathrm{H}_{2}$ gas production with $\mathrm{H}_{2}$ purification. The results reveal the importance of circulating fluidized bed gasification of groundnut shells in terms of $\mathrm{H}_{2}$ production. With the development of hydrogen purification technology, biomass will play an important role in the development of the hydrogen economy and a sustainable environment.

Acknowledgment

B.C. Lütfüoğlu thanks to the support given by the Internal Project of Excellent Research of the Faculty of Science of University Kralove 2019.

\section{ORCID}

B.C. Lütfüoğlu

iD $0000-0001-6467-5005$

E. Pehlivan

Z. Akyürek

A.Ö. Akyüz

$0000-0002-7839-2572$

0000-0003-3102-4278

A. Güngör

$0000-0001-9265-7293$

0000-0002-4245-7741

\section{References}

[1] International Energy Agency Report, 2017. www.iea.org/publications/freepublications/ (19 September2019). 
[2] Deborah, P., Francesca, V. and Giuseppe, G. 2015. Analysis of the environmental impact of a biomass plant for the production of bioenergy. Renewable and Sustainable Energy Reviews, 51, 634-647.

[3] Eghtedaei, R., Mirhosseini, S. A., Esfahani, M. J., Foroughi, A. and Akbari, H. 2017. Co-gasification of biomass and municipal solid waste for hydrogen-rich gas production. Energy Sources, Part A: Recovery, Utilization, and Environmental Effects, 39(14), 14911496.

[4] Xiang, X., Gong, G., Shi, Y., Cai, Y. and Wang, C. 2018. Thermodynamic modeling and analysis of a serial composite process for biomass and coal co-gasification. Renewable and Sustainable Energy Reviews, 82, 27682778.

[5] Mahapatra, S. and Dasappa, S. 2014. Influence of surface area to volume ratio of fuel particles on gasification process in a fixed bed. Energy for Sustainable Development, 19, 122-129.

[6] Panwar, N. L., Kothari, R. and Tyagi, V. V. 2012. Thermo chemical conversion of biomass - ecofriendly energy routes. Renewable and Sustainable Energy Reviews, 16(4), 1801-1816.

[7] Sansaniwal, S. K., Pal, K., Rosen, M. A. and Tyagi, S. K. 2017. Recent advances in the development of biomass gasification technology: A comprehensive review. Renewable and sustainable energy reviews, 72, 363-384.

[8] Saxena, R. C., Seal, D., Kumar, S. and Goyal, H. B. 2008. Thermo-chemical routes for hydrogen rich gas from biomass: a review. Renewable and Sustainable Energy Reviews, 12(7), 1909-1927.

[9] Son, Y. I., Yoon, S. J., Kim, Y. K. and Lee, J. G. 2011. Gasification and power generation characteristics of woody biomass utilizing a downdraft gasifier. Biomass and Bioenergy, 35(10), 4215-4220.

[10] Chang, A. C., Chang, H. F., Lin, F. J., Lin, K. H. and Chen, C. H. 2011. Biomass gasification for hydrogen production. International Journal of Hydrogen Energy, 36(21), 14252-14260.

[11] Dasappa, S., Subbukrishna, D. N., Suresh, K. C., Paul, P. J. and Prabhu, G. S. 2011. Operational experience on a grid connected $100 \mathrm{kWe}$ biomass gasification power plant in Karnataka, India. Energy for sustainable development, 15(3), 231-239.

[12] Jimenez, O., Curbelo, A. and Suarez, Y. 2012. Biomass based gasifier for providing electricity and thermal energy to off-grid locations in Cuba. Conceptual design. Energy for Sustainable Development, 16(1), 98-102.

[13] Vera, D., Jurado, F., Margaritis, N. K. and Grammelis, P. 2014. Experimental and economic study of a gasification plant fuelled with olive industry wastes. Energy for Sustainable Development, 23, 247-257.

[14] Ahmad, A. A., Zawawi, N. A., Kasim, F. H., Inayat, A. and Khasri, A. 2016. Assessing the gasification performance of biomass: A review on biomass gasification process conditions, optimization and economic evaluation. Renewable and Sustainable Energy Reviews, 53, 1333-1347.

[15] Wang, Y. and Zhang, S. 2017. Economic assessment of selected hydrogen production methods: A review. Energy Sources, Part B: Economics, Planning, and Policy, 12(11), 1022-1029.

[16] E.Tool Box, Fuels higher and lower calorific values, 2003.www.engineeringtoolbox.com/fuels-highercalorific-values-d_169.html. (13 September 2019.)

[17] Sharma, S. and Sheth, P. N. 2016. Air-steam biomass gasification: experiments, modeling and simulation. Energy conversion and management, 110, 307-318.

[18] Zhao, L. and Lu, Y. 2018. Hydrogen production by biomass gasification in a supercritical water fluidized bed reactor: A CFD-DEM study. The Journal of Supercritical Fluids, 131, 26-36.

[19] Cui, H. and Grace, J. R. 2007. Fluidization of biomass particles: A review of experimental multiphase flow aspects. Chemical Engineering Science, 62(1-2), 45-55.

[20] Wang, S., Luo, K., Hu, C., Sun, L. and Fan, J. 2018. Impact of operating parameters on biomass gasification in a fluidized bed reactor: An Eulerian-Lagrangian approach. Powder Technology, 333, 304-316.

[21] Behainne, J. J. R. and Martinez, J. D. 2014. Performance analysis of an air-blown pilot fluidized bed gasifier for rice husk. Energy for Sustainable Development, 18, 75-82.

[22] Lv, P.M., Xiong, Z.H., Chang, J., Wu, C.Z., Chen, Y. and Zhu, J.X., 2004. An experimental study on biomass air-steam gasification in a fluidized bed. Bioresource Technology, 95(1), 95-101.

[23] Campoy, M., Gomez-Barea, A., Vidal, F.B. and Ollero, P., 2009. Air-steam gasification of biomass in a fluidised bed: process optimisation by enriched air. Fuel Processing Technology, 90(5), 677-685.

[24] Gil-Lalaguna, N., Sánchez, J.L., Murillo, M.B., Rodríguez, E. and Gea, G., 2014. Air-steam gasification of sewage sludge in a fluidized bed. Influence of some operating conditions. Chemical Engineering Journal, 248, 373-382.

[25] Yan, L., Li, Y., Yang, B., Farahani, M.R. and Gao, W., 2018. Air-steam gasification of municipal solid wastes (MSWs) for hydrogen production. Energy Sources, Part A: Recovery, Utilization, and Environmental Effects, 40(5), 538-543. 
[26] Kuhe, A. and Aliyu, S.J., 2015. Gasification of' Loose'Groundnut Shells in a Throathless Downdraft Gasifier. International Journal of Renewable Energy Development, 4(2), 125-130

[27] Worldatlas, Where are Peanuts Grown?, 2019. https://www.worldatlas.com/articles/top-peanutgroundnut-producing-countries.html. (19 September 2019.)

[28] Jarungthammachote, S. and Dutta, A., 2007. Thermodynamic equilibrium model and second law analysis of a downdraft waste gasifier. Energy, 32(9), 1660-1669.

[29] Costa, M., Massarotti, N., Cappuccio, G., Chang, C.T., Shiue, A., Lin, C.J. and Wang, Y.T., 2014. Modeling of syngas production from biomass energy resources available in Taiwan. Chemical Engineering, 37, 343348.

[30] Xi, W., Shi, Z., Farahani, M.R. and Gao, W., 2017. Computer simulation of coal gasification in a full scale plant. Energy Sources, Part A: Recovery, Utilization, and Environmental Effects, 39(8), 768-774.

[31] La Villetta, M., Costa, M. and Massarotti, N., 2017. Modelling approaches to biomass gasification: A review with emphasis on the stoichiometric method. Renewable and Sustainable Energy Reviews, 74, 71-88.

[32] Gungor, A., Ozbayoglu, M., Kasnakoglu, C., Biyikoglu, A. and Uysal, B.Z., 2012. A parametric study on coal gasification for the production of syngas. Chemical Papers, 66(7), 677-683.

[33] Kocer, A., Yaka, I.F. and Gungor, A., 2017. Evaluation of greenhouse residues gasification performance in hydrogen production. International Journal of Hydrogen Energy, 42(36), 23244-23249.

[34] Sansaniwal, S.K., Rosen, M.A. and Tyagi, S.K., 2017. Global challenges in the sustainable development of biomass gasification: An overview. Renewable and Sustainable Energy Reviews, 80, 23-43.

[35] Groppi, G., Tronconi, E., Forzatti, P. and Berg, M., 2000. Mathematical modelling of catalytic combustors fuelled by gasified biomasses. Catalysis Today, 59(12), 151-162.

[36] Gungor, A. and Yildirim, U., 2013. Two dimensional numerical computation of a circulating fluidized bed biomass gasifier. Computers \& Chemical Engineering, 48, 234-250.

[37] Natarajan, E. and Baskara Sethupathy, S., 2015. Gasification of groundnut shells. Energy Sources, Part A: Recovery, Utilization, and Environmental Effects, 37(9), 980-986.

[38] Nisamaneenate, J., Atong, D., Sornkade, P. and Sricharoenchaikul, V., 2015. Fuel gas production from peanut shell waste using a modular downdraft gasifier with the thermal integrated unit. Renewable Energy, 79, 45-50.

[39] Alzate, C.A., Chejne, F., Valdés, C.F., Berrio, A., De La Cruz, J. and Londoño, C.A., 2009. CO-gasification of pelletized wood residues. Fuel, 88(3), 437-445.

[40] Kaushal, P., Pröll, T. and Hofbauer, H., 2007. Model development and validation: co-combustion of residual char, gases and volatile fuels in the fast fluidized combustion chamber of a dual fluidized bed biomass gasifier. Fuel, 86(17-18), 2687-2695.

[41] Kirubakaran, V., Sivaramakrishnan, V., Nalini, R., Sekar, T., Premalatha, M. and Subramanian, P., 2009. A review on gasification of biomass. Renewable and Sustainable Energy Reviews, 13(1), 179-186.

[42] Subbaiah, B.S., Murugan, D.K., Deenadayalan, D.B. and Dhamodharan, M.I., 2014. Gasification of biomass using fluidized bed. International Journal of Innovative Research in Science, Engineering and Technology, 3(2), 8995-9002. 